\title{
Cytotoxicity of seven recent dentine bonding agents on mouse 3T3 fibroblast cells
}

\author{
Annette Olivier, Sias R. Grobler, Yusuf Osman \\ Faculty of Dentistry, Oral and Dental Research Institute, University of the Western Cape, Cape Town, South Africa \\ Email: srgrobler@uwc.ac.za
}

Received 20 October 2012; revised 21 November 2012; accepted 30 November 2012

\begin{abstract}
Today it is generally accepted that most bonding agents are cytotoxic. In this study the relative cytotoxicity of seven recent dentine bonding agents on mouse 3T3 fibroblast cells were investigated. Materials and Methods. Near-confluent mouse 3T3 fibroblast cells were exposed to Dulbecco Modified Eagle's Medium containing extractions from the seven different bonding agents. The cell survival rate was then determined using the standard MTT assay. Results. The cell survival rate ranking is: iBond $(94 \%)<$ Gbond $\mathbf{( 7 8 \% )}<$ Xeno V $\mathbf{( 7 1 \% )}<$ Adper Easy Bond $(63 \%)<$ Xeno V+ $(61 \%)<$ Adper Scotchbond SE (33\%) < XP Bond (32\%). Part A of Adper Scotchbond SE had a survival rate of $35 \%$ and part $B 38 \%$. These two parts did not differ significantly. Adper Scotchbond SE and XP Bond do not differ significantly. While Xeno V+, Xeno V and Adper Easy Bond do not differ. ( $<$ 5\%; Tukey-Kramer Multiple-Comparison Test). Conclusion. All of the tested adhesive bonding agents were cytotoxic with survival rate of $3 \mathrm{~T} 3$ cells between $94 \%$ to $31 \%$. Of the 7 bonding agents tested iBond was found to be only slightly toxic and by far the least toxic. The two bonding agents (XP Bond and Adper Scotchbond SE) containing UDMA plus TEGDMA plus HEMA plus camphorquinone were found to be the most toxic.
\end{abstract}

Keywords: Cytotoxicity; Bonding Agents; Mouse 3T3 Fibroblast

\section{INTRODUCTION}

Knowledge of the biocompatibility of dental materials is important so as to prevent hazardous effects on the surrounding tissues where it is placed. Different bonding agents are used in combination with different resins to provide a possible effective long lasting restoration [1-3].

In an attempt to simplify the bonding technique, manufacturers over the years strived to decrease the number of steps needed to accomplish successful bonding. Two- step-etch and rinse and one step self-etch bonding agents were introduced. They gained rapid popularity because of their relative ease of use [4]. One step adhesives were made both acidic and hydrophilic to blend all adhesive components into one single solution. Available dental bonding agents which are used to bond resins to enamel and dentin differ in composition as well as proportions there-off. It is believed that the chemical formulation determines the success of the adhesive in the clinical situation. However, research done on the biocompatibility of dental bonding agents [5] and the ingredients showed that many of the constituents to be cytotoxic [6]. The cytotoxic effects of monomers have also been reported in several in vitro studies [2,7-16].

The normal composition of bonding agents are: resin monomers, initiators, inhibiters or stabilizers, solvents and sometimes inorganic fillers [17]. These components may be released from the resin systems due to incomeplete polymerization and later due to degradation which resulted in potential adverse clinical effects $[14,18,19]$. Trubiani [15] supported finding of other researchers [14, 20] and conclude that research indicated that resin components such as TEGDMA, HEMA, bis-GMA, UDMA are a likely cause of cellular stress and that they have significant cytotoxic effects. However, HEMA were frequently been used as a wetting agent and therefore competes with water for penetration into the dentine. It also copolymerizes with other resin composite monomers [21]. The release of many monomers were investigated but still limited info on the effect of released quantities of additives such as initiators, inhibitors and stabilizers is known [22]. Ratanasathien [2] suggested that it is possible that synergistic interaction between the multiple components may occur resulting in more cytotoxicity than the individual components would have caused by themselves.

Several of the dental adhesives examined were tested in vitro studies where various established cell-lines were used in vitro. The two primary advantages of this type of testing is the ability to control the environment in the laboratory and the subsequent ability to accurately meas- 
ure the response to the exposed cells. These tests prove to be rapid, inexpensive, sensitive and a repeatable means of ranking the cytotoxicity of dental materials [23].

Improving the clinical behaviour of adhesives and reducing the risk of cytotoxicity can be achieved by adjusting the (proportion and/or amounts) ingredients in adhesives or to develop new monomers [17] with completely new chemicals.

Therefore, the purpose of this study was to determine the cytotoxicity of quite recent dentine bonding agents from different manufacturers.

\section{MATERIALS AND METHODS}

A Balb/c 3T3 mouse fibroblast cell line (The National Repository for Biological Materials, Sandringam) was maintained and cultured in standard conditions $\left(37^{\circ} \mathrm{C}\right.$ under 5\% carbon dioxide and 95\% humidity) in Dulbecco's Modified Eagles Medium (DMEM). The medium was supplemented with $10 \%$ fetal bovine serum $1 \%$ penicillin, $1 \%$ streptomycin and $0.2 \%$ fungizone, changed every second day and cells sub-cultured using routine trypsin/EDTA procedures.

For the testing of the cytotoxicity of the bonding agents, an indirect modified model [24] adapted from "the model cavity method" [25] was used (Figure 1).

An example of the construction of such a test bottle is shown (Figure 1). Briefly, the model consisted of a screw top with an $8 \mathrm{~mm}$ circular hole in the center which was covered with a permeable membrane. In this way the cap formed an opening (cavity) of $1.5 \mathrm{~mm}$ deep, with a surface area of $50.3 \mathrm{~mm}^{2}$, which was loaded with $8 \mu \mathrm{l}$ of bonding agent and light cured according to each manufacturer's instructions. The sample bottles were then inverted to expose the $400 \mu \mathrm{l}$ medium to the bonding agent through the membrane and placed in an incubator at $37^{\circ} \mathrm{C}$ for 24 hours. Any toxin, if present in the sample to be tested, will then leach out through the membrane barrier into the DMEM. Ten sample bottles were used for

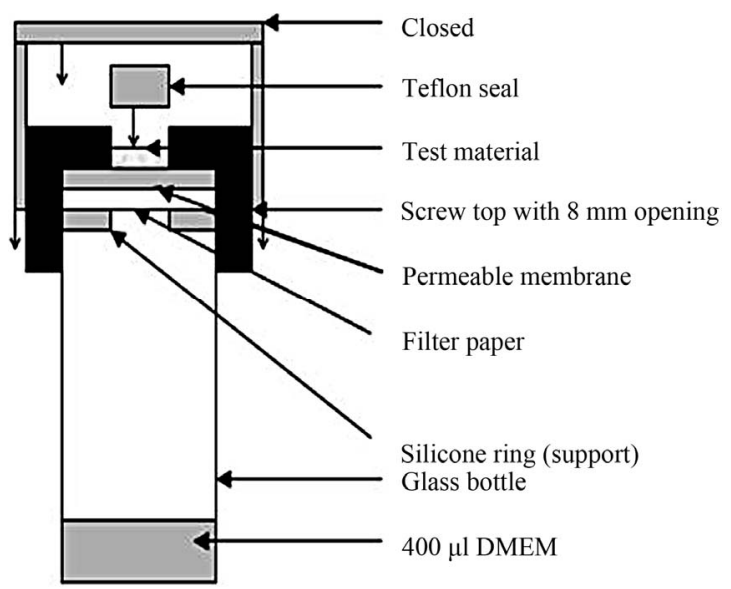

Figure 1. Schematic drawing of a test bottle. each of the bonding agents.

For cytotoxicity testing, 3T3 cells in the active growth phase displaying $80 \%$ - $90 \%$ confluence were sub-cultured and diluted to a final cell suspension containing approximately $3 \times 10$ (5) cells $/ \mathrm{ml}$. Cells were plated out in a 96 well plate , 20 wells for each bonding agent (each sample divided into 2 wells) with 10 extra wells to act as controls. On day two the $400 \mu \mathrm{l}$ of exposed eluate from each of the 10 bottles was used to replace the medium in the 20 wells $(200 \mu \mathrm{l} /$ well). The culture medium of the controls was replaced with fresh DMEM. After 24 hours the widely used MTT colorimetric assay was used to evaluate toxicity. This assay involves the ability of viable cells to use mitochondrial dehydrogenase enzymes to convert MTT (a soluble tetrazolium salt) to a blue/violet formazan end product [26]. $20 \mu \mathrm{l}$ MTT $(5 \mathrm{mg} / \mathrm{ml}$ in phosphate-buffered solution) was added to each well and left for a further 3 hours to incubate at $37^{\circ}$. The medium was discarded to eliminate the MTT and the precipitated formazan crystals were solubilized with $100 \mu \mathrm{l} /$ well of dimethylsulfoxide (DMSO). Cells with medium not exposed to bonding agent were used as negative controls. Absorbance was measured at wavelength $540 \mathrm{~nm}$ on a spectrophotometer to determine the number of viable cells. Every dental material was tested 3 times.

The bonding agents (Table 1) tested were XP Bond, Adper Scotchbond SE, Adper Easy Bond, Gbond, Xeno $\mathrm{V}$, Xeno V+ and iBond.

Only one product Scotchbond SE is a 2-step system (all 6 others being one step systems) with components A and $\mathrm{B}$. In this case the two components were also tested separately.

\section{RESULTS}

The Box and Whisker plots (Figure 2) were used to compare distributions resulting from the different survival rates of the 7 bonding agents.

Due to the differences in dispersion the Tukey-Kramer Multiple-Comparison Test was used to compare the locality of the 7 bonding agents. The Box and Whisker plot (Figure 2) shows the percentage viable cells of the different bonding agents. Each Box plot shows the median percentage viable 3T3 cells, 1st quartile value, 2nd quartile value, maximum and minimum values. The region between the 1st and 3rd quartiles shows the location of $50 \%$ of the values.

The sample sizes were uni-model but relatively small. Therefore, nonparametric tests were employed and the Kruskal-Wallis test used on the medians to indicate whether differences existed. The Tukey-Kramer Multiple-Comparison Test was used to test for significant differences between pairs of bonding agents.

Table 2 shows the results of the Tukey-Kramer statistical tests based on a 5\% significant level. Median values 
Table 1. Chemical composition and batch numbers of the seven bonding agents.

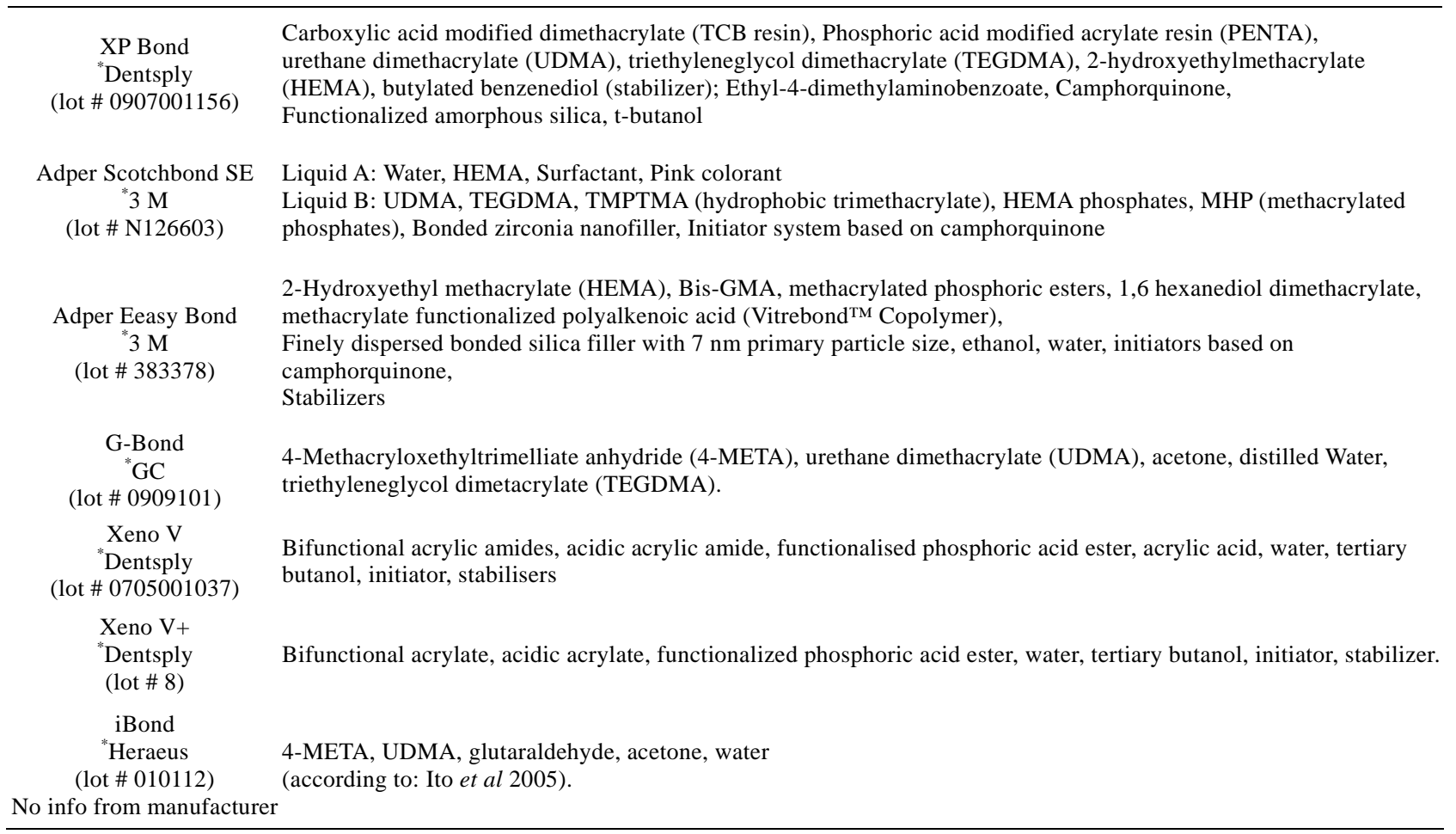

*Dentsply, New York, USA; 3 M St.Paul MN USA; GC Corporation, Tokyo, Japan; Heraeus Holding GmbH, Hanau, Germany.

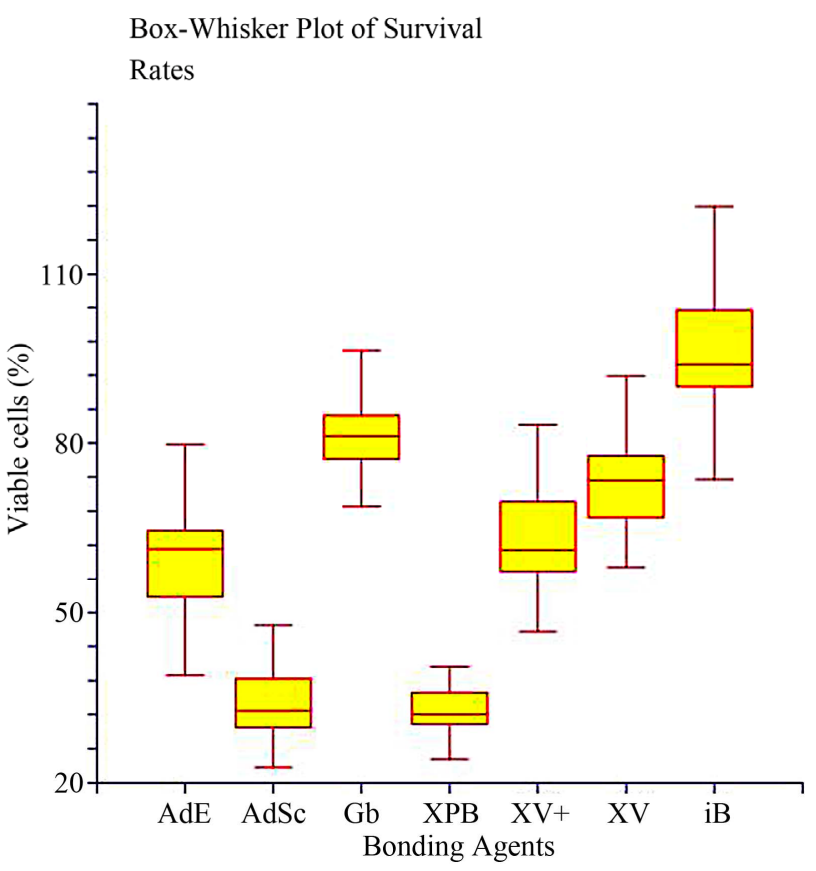

Figure 2. The Box-Whisker plot of the \% survival rate of mouse 3T3 fibroblast cells when exposed to XP Bond (XPB; 31.9\%), AdperScotchbond SE (AdSc; 32.5\%), Xeno V+ (XV+; 61.4\%), Adper Easy Bond (AdE; GB; 63.0\%), Xeno V (XV; 71.4\%), G-Bond (GB; 78.3\%) and iBond (iB; 94.2\%). The maximum and minimum values are given. The intermediary box represents the position of $50 \%$ of the values and the line within the box shows the median values. not significantly $(\mathrm{p}>0.05$ ) different were linked by a horizontal line.

Figure 3 shows a typical example of damaged cells at 100× magnification: (a) healthy mouse 3T3 fibroblast cells and (b) cells exposed for 24 hours to the bonding agent XP Bond (damaged cells).

Adper Scotchbond SE Self-Etch consisted of two parts ((a) and (b)) were also tested separately. The cell survival rate of Part (a) (35\%) and (b) (38\%) did not differ significantly. However, the combination of the two gave a significant lower survival rate (33\%) than Part (a) or Part (b).

\section{DISCUSSION}

A few factors would have a significant influence on the survival rate of cells. Firstly, the concentration of the bonding agent to which the cells were exposed. In general, it can be expected that a higher concentration should result in a lower number of survival cells and vice versa [27]. Koulaouzidou [27] supported this statement with studies on 3 different bonding agents where cell viability decreased in a dose dependant manner after exposure. The recommended concentration range (ANSI/ADA [28]) for extraction studies for biological evaluation of dental materials is $0.5 \mathrm{~cm}^{2} / \mathrm{ml}$ to $6 \mathrm{~cm}^{2} / \mathrm{ml}$. In our study the area to volume ratio was calculated to be $1.26 \mathrm{~cm}^{2} / \mathrm{ml}$, which is well in the recommended range. However, many stud- 
Table 2. Results of the Tukey-Kramer statistical tests. Median values not significantly $(\mathrm{p}>0.05)$ different werelinked by a horizontal line.

\begin{tabular}{cccc}
\hline \multicolumn{2}{c}{ AdE XV XV+ } & \multicolumn{2}{c}{ AdSc XPB } \\
\hline \multirow{4}{*}{${ }^{*}$ Where: } & AdE & -- & Adper Easy Bond \\
& XV & -- & Xeno V \\
& XV+ & -- & Xeno V plus \\
& AdSc & -- & Adper Scotchbond SE \\
& XPB & --- & XP Bond \\
\hline
\end{tabular}

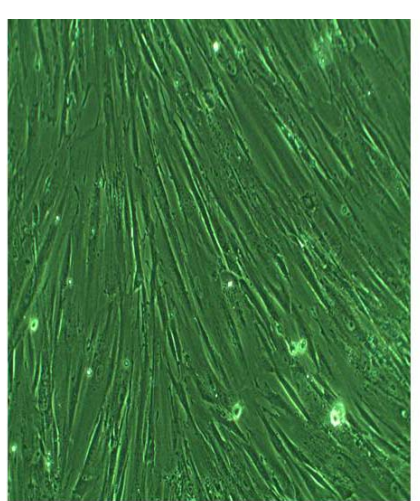

(a)

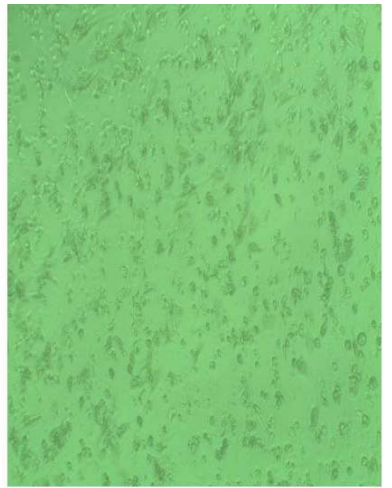

(b)
Figure 3. Images (100× magnification) of undamaged mouse 3T3 fibroblast cells (a) and damaged (b) cells.

ies ignore the concentration setting and add different dilutions (even in some cases drops of the material) to different volumes and it is therefore difficult to compare results meaningfully.

Secondly, it can be expected that different cell-lines would result in different survival rates (although it might be small, [5]). It was suggested [2] that 3T3 mouse fibroblast cells should be used for the cytotoxicity testing of dental materials because these cells display properties similar to cells in vivo. Wataha [29] stated that 3T3 cells (also used in this study) compare well with primary cell lines in their cytotoxic response.

Thirdly, whether cured or uncured bonding agents were tested will also affect the results. In this study, we only used cured dentine bonding agents from where extractions were made.

Fourthly, the time-period of exposure to the cells would also influence the results. Moharamzadeh [30] stated that exposure time is an important parameter in cytotoxicity studies although several researchers used different time periods [31-33]. Moharamzadeh [30] suggested a $24 \mathrm{hr}$ time-period because monomer release from the resin should be completed in 24 hrs and therefore most toxic effects from the resins will occur during the first $24 \mathrm{hrs}$. This was also supported by the set standards (ANSI/ADA). Sigusch [33] stated that the major part of the release of toxic substances into the medium occurs during the first hours or days after polymerization. Therefore, an exposure time of 24 hrs were also selected in our study.

In our study tests were done in pairs, simultaneously (control vs test samples), to accommodate possible differences in cell-growth over batches. Then to statisticcally calculate the \% viable cells between the controls and the test samples, a standardization process was done by dividing each raw test value (in the presence of the bonding agent) by the median of the corresponding control survival value.

All 7 of the tested materials were found to be cytotoxic however, to varying degrees. The sequence of the degree of cytotoxicity found (Figure 2) was: iBond < Gbond $<$ Xeno V $<$ Adper Easy Bond $<$ Xeno V $+<$ Adper Scotchbond SE $<$ XP Bond.

Certain generally used resin monomers (like BisGMA and UDMA) and co-monomers (like TEGDMA and HEMA) were reported to be cytotoxic. The general rank of toxicity was found to be: BisGMA > UDMA > TEGDMA >> HEMA [2,7-14].

BisGMA was found in Adper Easy Bond, (Table 1), UDMA in Adper Scotchbond SE, iBond, XP Bond and Gbond and TEGDMA in Adper Scotchbond SE, XP Bond, G-Bond and HEMA in Adper Easy Bond, Adper Scotchbond and XP Bond. It can be seen from our results (Figure 2) that the bonding agents (XP Bond, and Adper Scotchbond SE) containing three of the mentioned toxic components (TEGDMA, UDMA, HEMA) were also found to be the most cytotoxic of the 7 bonding agents. Furthermore, XP Bond, and Adper Scotchbond SE in addition also contained the photo-initiator camphorquinone which is reported to be cytotoxic [34-37].

Ratanasthien [2] stated that both the concentration of the components and the duration of the test showed effects on the survival rates. In this way they [2] reported increased cytotoxicity after a $24 \mathrm{~h}$ period but decreased cytotoxicity after 78 hrs. Furthermore, in general the higher the molecular weight of the component the higher the degree of cytotoxicity (e.g. BisGMA $=512$, UDMA $=471$, TEGDMA = 286, HEMA = 130) [12].

Of the bonding agents tested in this study only Adper Scotchbond SE has 2 components (A \& B) and these were also tested separately. However, the combination of A \& B gave a significant lower survival rate. Thus, in this study it seemed that the polymerization process worsened the survival rate. However, it was also reported that the combined action of UDMA and TEGDMA was found to be lesser than the individual components [38] and that polymerised bonding agents exhibited lower cytotoxicity than the un-polymerised [32].

The only difference in the composition between Xeno $\mathrm{V}$ and Xeno $\mathrm{V}+$ was that Xeno $\mathrm{V}+$ did not contain acrylic acid which was supposed to improve the smell of the bonding agent. However, the 2 bonding agents did not show a significant difference in the cytotoxicity. El- 
kholany [39] reported that Xeno V had a remarkable adverse effect on odontoblasts (weaker than Xeno III). Porto [38] found it to be cytotoxic even through a dentine barrier, while Tuncer [3] reported Xeno V to be $50 \%$ less cytotoxic than XP Bond. In this study Xeno V (67\%, survival rate) was also found to be far less cytotoxic than XP Bond (32\%; Figure 2).

As in this study (although on mesenchymal stem cells) Trubiani [15] also reported a high cytotoxic effect for XP Bond (30\% survival rate) which corresponds well with the 32\% found (Figure 2), while Koulaouzidou [27] reorted even lower values (about 10\%) for XP Bond and that cell viability (L929 cell-line) decreased in a dose dependant manner. However, their bonding agent concentration was much higher (5\% plus) than ours at $2 \%$. XP Bond was also found to be concentration dependent when tested on RPC-C2A and L929 cells, with low survival rates [27].

In total contrast to our study (94\% survival rate), Vajrabhaya [40] reported that iBond was the most toxic material (even more than Xeno III) with only a $10 \%$ survival rate. Sigusch (2009) also reported a low survival rate $(\sim 10 \%)$ although on human gingival fibroblasts. This contrast could lie in the composition of iBond which since might have been changed as no precise information on the composition could be obtained from the manufacturer as it is a business secret. We only gave the composition as reported by Ito [41].

Although G-Bond contained UDMA and TEGDMA the survival rate (78\%) was found to be the second best of the 7 bonding agents tested (Figure 2). A relatively high survival rate (63.5\%) was also reported [32] for polymerized G-Bond after 24 hrs.

Thus, from this study the presence of many of the known harmful (three or more) components could be used as an indication to predict the possible cytotoxic effect of a bonding agent. Figure 3 shows a typical example of undamaged as well as damaged 3T3 cells. No difference in the images of damaged cells could be seen amongst the 7 different bonding agents.

To conclude, of the 7 bonding agents tested iBond was found to be only slightly toxic and by far the least toxic. The two bonding agents (XP Bond and Adper Scotchbond SE) containing UDMA plus TEGDMA plus HEMA plus camphorquinone were found to be the most toxic. The success of a bonding agent depends on the composition/chemistry of the specific agent as well as the knowledge of the possible damage the agent can cause on the surrounding dental tissue. This article tended to contribute to that knowledge to assist in the selection of dental materials.

\section{ACKNOWLEDGEMENTS}

This study is financially supported by the DDF fund of the South Afri- can Dental Association. Disclaimer: The South African Dental Association does not necessarily support the findings or conclusions made in this article.

\section{REFERENCES}

[1] Chen, R.S., Liu, C.C., Tseng, W.Y., Jeng, J.H. and Lin, C.P. (2003) Cytotoxicity of three dentin bonding agents on human dental pulp cells. Journal of Dentistry, 31, 223-229. doi:10.1016/S0300-5712(02)00088-X

[2] Ratanasathien, S., Wataha, J.C., Hanks, C.T. and Dennison, J.B. (1995) Cytotoxic interactive effects of dentin bonding components on mouse fibroblasts. Journal of Dental Research, 74, 1602-1606. doi:10.1177/00220345950740091601

[3] Tuncer, S., Demirci, M., Schweikl, H., Erguven, M., Bilir, A. and Tuncer, A.K. (2012) Inhibition of cell survival, viability and proliferation by dentin adhesives after direct and indirect exposure vitro.

[4] Cardoso, M.V. (2011) Current aspects on bonding effecttiveness and stability in adhesive dentistry. Australian Dental Journal, 56, 31-44. doi:10.1111/j.1834-7819.2011.01294.x

[5] Grobler, S.R., Olivier, A., Moodley, D, and van W Kotze, T.W. (2004) Cytotoxicity of two concentrations of a dentine bonding agent on mouse 3T3 and human pulp fibroblast cell-lines. South African Dental Journal, 59, 368370.

[6] Wataha, J.C. (2012) Predicting clinical biological responses to dental materials. Dental Materials, 28, 23-40. doi:10.1016/j.dental.2011.08.595

[7] Szep, S., Kunkel, A., Ronge, K. and Heideman D. (2002) Cytotoxicity of modern dentin adhesives-In vitro testing on gingival fibroblasts. Journal of Biomedical Materials Research, 63, 53-60. doi:10.1002/jbm.10083

[8] Hashieh, I.A., Franquin, J.C., Cosset, A. and Dejou, J. (1998) Relationship between dentin hydraulic conductance and the cytotoxicity of four dentin bonding resins in vitro. Journal of Dentisty, 26, 473-477.

[9] Hashieh, I.A., Cosset, A., Franquin, J.C. and Camps, J. (1999). In vitro cytotoxicity of one-step dentin bonding systems. Journal of Endodontics, 25, 89-92. doi:10.1016/S0099-2399(99)80003-X

[10] Vajrabhaya, L., Pasasuk, A. and Harnirattisai, C. (2003) Cytotoxicity evaluation of single component dentin bonding agents. Oral Surgery, Oral Medicine, Oral Pathology, Oral Radiology and Endodontology, 28, 440-444. doi:10.1016/j.tripleo.2008.11.008

[11] Rathbun, M.A., Craig, R.G., Hanks, C.T. and Filisko, F.E. (1991) Cytotoxicity of a Bis-GMA dental composite before and after leaching in organic solvents. Journal Biomedical material Research, 25, 443-457. doi:10.1002/jbm.820250403

[12] Geurtsen, W., Lehman, F., Spahl, W. and Leyhausen, G. (1998) Cytotoxicity of 35 dental resin composite monomers/additives in permanent 3T3 and three human primary fibroblast cultures. Journal of Biomedical Materials Research, 41, 474-480. 
[13] Schmalz, G. (1998) The biocompatibility of non-amalgam dental filling materials. European Journal of Oral Sciences, 2, 696-706. doi:10.1046/j.0909-8836.1998.eos10602ii05.x

[14] Hanks, C.T., Strawn, S.E., Watahai, J.C. and Craig, R.G. (1991) Cytotoxic effects of resin components on cultured mammalian fibroblasts. Journal of Dental Research, 70, 1450-1455.

[15] Trubiani, O., Caputi, S., Di Iorio, D., et al. (2010) The cytotoxic effect of resin-based sealers on dental pulp stem cells. International Endodontic Journal, 43, 451-452. doi:10.1111/j.1365-2591.2010.01729.X

[16] Harorli, O.T., Bayindir, Y.A., ltunkaynak, Z. and Tatar, A. (2009) Cytotoxic effects of TEGDMA on THP-1 cells in vitro. Medicina Oral Patologia Oral Cirugia Bucal, 14, e489-e493.

[17] Van Landuyt, K.L., Snauwaert, J., De Munck, J., et al. (2007) Systematic review of the chemical composition of contemporary dental adhesives. Biomaterials, 28, 37573785. doi:10.1016/j.biomaterials.2007.04.044

[18] Yeh, H., Chang, M., Lin, C., et al. (2009) Comparative cytotoxicity of five current dentin bonding agents: Role of cell cycle deregulation. Acta Materialia, 5, 3404-3410. doi:10.1016/j.actbio.2009.05.036

[19] Issa, Y., Watts, D.C., Brunton, P.A., Waters, C.M. and Duxbury, A.J. (2004) Resin composite monomers alter MTT and LDH activity of human gingival fibroblasts in vitro. Dental Materials, 20, 12-20. doi:10.1016/S0109-5641(03)00053-8

[20] Goldberg, M. (2008) In vitro and in vivo studies on the toxicity of dental resin components: A review. Clinical Investigations, 12, 1-8.

[21] Peutzfeldt, A. (1997) Retention of propanal and diacetyl in experimental resins. Acta Odontologica Scandinavica, 55, 94-100. doi:10.3109/00016359709115399

[22] Van Landuyt, K.L., Nawrot, T., Geebelen, B., et al. (2011) How much do resin based materials release? A metaanalytical approach. Dental Materials, 27, 723-747.

[23] Koulaouzidou, E.A., Helvatjoglu-Antoniades, M., Palaghias, G., Karaniuka-Kouma, A. and Antoniades, D. (2009) Cytotoxicity of dental materials in vitro. European Journal of Dentistry, 3, 3-9.

[24] Grobler, S.R., Basson, N.J. and Rossouw, R.J. (1996) Shear bond strength, microleakage and antimicrobial properties of Aelitebond. American Journal of Dentisty, 9, 120-124.

[25] Grobler, S.R., Olivier, A., Moodley, D. and Van Wyk Kotze, T.J. (2008) Cytotoxicity of recent bonding agents on mouse fibroblast cells. Quintessence International, 39, 511-516.

[26] Mosmann, T. (1983) Rapid colorimetric assay for cellular growth and survival: Application to proliferation and cytotoxicity assays. Journal of Immunological Methods, 65, 55-63. doi:10.1016/0022-1759(83)90303-4

[27] Koulaouzidou, E.A., Konstantinos, T.P., Yiannaki, M.D. and Papazisis, G. (2009) Effects of dentin bonding agents on the cell cycle of fibroblasts. Journal of Endodontics, 35, 275-279. doi:10.1016/j.joen.2008.11.013
[28] American National Standards Institute and American Dental Association (2000) Revision, document no. 41 for recommended standard practices for biological evaluation of dental materials.

[29] Wataha, J.C., Hanks, C.T. and Sun, Z. (1994) Effect of cell-line on in vitro metal ion cytotoxicity. Dental Materials, 10, 156-161.

[30] Moharamzadeh, K., Van Noort, R., Brook, I.M. and Scutt, A.M. (2007) Cytotoxicity of resin monomers on human gingival fibroblasts and HaCaT keratinocytes. Dental Materials, 23, 40-44. doi:10.1016/j.dental.2005.11.039

[31] Koliniotou-Koubia, E., Dionysopoulos, P., Koulaouzidou, E.A., Kortsaris, A.H. and Papadogiannis, Y. (2001) In vitro cytotoxicity of six dentin bonding agents. Journal of Oral Rehabilitation, 28, 971-975. doi:10.1046/j.1365-2842.2001.00769.X

[32] Yasuda, Y., Inuyama, H., Maeda, H., Akamine, A., Nör, J.E. and Saito, T. (2008) Cytotoxicity of one step bonding agents toward dental pulp and odontoblast-like cells. Journal of Oral Rehabilitation, 35, 940-946. doi:10.1111/j.1365-2842.2008.01885.x

[33] Sigusch, B.W., Pflaum, T., Völpel, A., Schinkel, M. and Jandt, K.D. (2009) The influence of various light curing units on the cytotoxicity of dental adhesives. Dental Materials, 25, 1446-1452. doi:10.1016/j.dental.2009.06.016

[34] Atsumi, T., Murata, J., Kamiyanagi, I., Fujisawa, S. and Ueha, T. (1998) Cytotoxicity of photosensitizers camphorquinone and 9-fluorenone with visible light irradiation on a human submandibular-duct cell line in vitro. Archives of Oral Biology, 43, 73-81. doi:10.1016/S0003-9969(97)00073-3

[35] Atsumi, T., Ishihara, M., Kadoma, Y., Tonosaki, K, and Fujisawa S. (2004) Comparative radical production and cytotoxicity induced by camphorquinone and 9-fluorenone against human pulp fibroblasts. Journal of Oral Rehabilitation, 12, 1155-1164. doi:10.1111/j.1365-2842.2004.01357.x

[36] Pagoria, D., Lee, A. and Geurtsen, W. (2005) The effect of camphorquinone (CQ) and cQ-related photosensitizers on the generation of reactive oxygen species and the production of oxidative DNA damage. Biomaterials, 26, 4091-4099. doi:10.1016/j.biomaterials.2004.10.022

[37] Okada, N., Muraoka, E., Fujisawa, S. and Machino, M. (2008) Effects of visible light-irradiated camphorquinone and 9-fluorenone on murine oral mucosa. Dental Materials Journal, 27, 809-813. doi:10.4012/dmj.27.809

[38] Porto, I.C.C.M., Oliveira, D.C., Raele, R.A., Ribas, K.H.S., Montes, M.A.J.R. and De Castro, C.M.M.B. (2011) Cytotoxicity of current adhesive systems: In vitro testing on cell cultures of primary murine macrophages. Dental Materials, 27, 221-228.

[39] EI-Kholany, N.R., Abielhassan, M.H., Elembaby, A.E. and Maria, O.M. (2011) Apoptotic effect of different selfetch dental adhesives on odontoblasts in cell culture. Archives of Oral Biology, 57, 775-783. doi:10.1016/j.archoralbio.2011.11.019

[40] Vajrabhaya, L.O., Korsuwannawong, S., Bosl, C., and Schmalz, G. (2009) The cytotoxicity of self-etching pri- 
mer bonding agents in vitro. Oral Surgery, Oral Medicine, Oral Pathology, Oral Radiology and Endodontology, 107, e86-e90. doi:10.1016/j.tripleo.2008.11.008
[41] Ito, S., Tay, F.R., Hashimoto, M., et al. (2005) Effects of multiple coatings of two all-in-one adhesives on dentin bonding. The Journal of Adhesive Dentistry, 7, 133-141. 